\title{
INTRODUÇÃO AO DEBATE SOBRE A ELEIÇÃO PRESIDENCIAL BRASILEIRA DE 1989
}

\section{An introduction to the debate on the 1989 presidential election in Brazil}

\author{
Luiz Miguel do Nascimento*
}

\begin{abstract}
RESUMO
A discussão que será realizada neste texto nasceu da constatação de que o estudo da política na década de 1980, em grande parte, vem sendo feito pela Ciência Política, Sociologia, Comunicação e Antropologia. A nosso ver, até o momento, salvo raras exceções, os historiadores não têm se dedicado a pesquisar essa temática no período em questão. Essa ausência é mais sentida, ainda, quando se trata da eleição presidencial brasileira de 1989. Assim sendo, este trabalho tem como objetivo realizar um diálogo com essas outras áreas do conhecimento que discutiram a referida eleição e trouxeram contribuições significativas para se entender esse importante momento da história política recente do nosso país. Além disso, sem abandonar os referenciais teóricos e metodológicos mais específicos da História, pretende-se defender a necessidade de essa disciplina se dedicar mais ao estudo do nosso presente, em particular o período compreendido entre as últimas duas décadas do século XX e os nossos dias.
\end{abstract}

Palavras-chave: história política; interdisciplinaridade; história do tempo presente.

\footnotetext{
ABSTRACT

The study of politics during the 1980s has been largely undertaken by Political Science, Sociology, Communication and Anthropology. It is the author's opinion that, as a general rule, historians have not devoted themselves to deepen research on this theme during the above period. This fact is greatly felt when the 1989 Brazilian presidential elections

* Professor Adjunto do Departamento de História da Universidade Estadual de Maringá.
} 
are discussed. Current research aims at dialoging with other sciences that have already discussed the election and have much contributed so that this important political event in Brazil could be understood. Without discarding the theoretical and methodological specific references to history, it is of paramount importance that history dedicates itself more to current events, especially the period comprising the last two decades of the $20^{\text {th }}$ century and the present.

Key-words: political history; interdisciplinarity; history of contemporaneity.

Ao iniciarmos este artigo, gostaríamos de destacar que a vida política brasileira dos anos 1980, seguramente uma das décadas mais importantes da nossa história na segunda metade do século XX até o momento, tem recebido muito pouca atenção dos historiadores. No tocante à história política desse período, em particular a eleição presidencial de 1989, a nossa disciplina, a História, tem estado praticamente ausente nos debates. Raros são os historiadores que discutem essa fase da nossa política recente. Com isso, as potenciais contribuições que a disciplina poderia trazer para as pesquisas sobre o tema não são devidamente exploradas. Assim sendo, a nosso ver, mais do que discutir a participação efetiva da História nos estudos sobre a política no período, temos de falar da sua ausência. Por essa razão, mesmo não sendo o objetivo central deste trabalho, na parte final do texto iremos fazer algumas considerações sobre a necessidade de a História estudar mais o nosso tempo presente e, ao mesmo tempo, apontaremos uma das contribuições que ela poderia trazer para a discussão sobre a eleição presidencial do final da década de 1980.

Em face do exposto, para se fazer uma avaliação dos estudos relativos à política brasileira da década de 1980, ou mais precisamente a eleição presidencial de 1989, como é o nosso caso, torna-se necessário recorrer às outras áreas das ciências humanas. Nesse sentido, o nosso trabalho tem como objetivo realizar um diálogo com a Ciência Política, a Sociologia, a área da Comunicação e a Antropologia, que discutiram a referida eleição e trouxeram contribuições significativas para se entender esse importante momento da história política recente do nosso país. Frise-se que não vamos fazer uma análise exaustiva de tudo o que foi produzido pelas outras áreas do conhecimento em relação à política no final da década de 1980. O nosso propósito restringe-se tão-somente a uma discussão de alguns textos que 
consideramos representativos das pesquisas que foram realizadas sobre essa temática no período, particularmente a disputa presidencial.

$\mathrm{Na}$ área do jornalismo, por exemplo, a maioria dos trabalhos que lemos não fazem uma análise em profundidade sobre a eleição. Como é da própria natureza dessa profissão, os textos geralmente procuram registrar os fatos mais marcantes da campanha eleitoral: comícios, debates, manifestações de personalidades empresariais e políticas, pesquisas de opinião pública, programas e temas discutidos pelos candidatos, além de alguns dos principais episódios que marcaram a eleição de 1989. Da mesma forma, em alguns desses trabalhos é possível encontrar informações sobre a biografia política dos principais candidatos daquela eleição, comentários a respeito dos problemas que cada um deles enfrentou dentro de suas legendas com a formação das alianças e, como é comum nas campanhas políticas no Brasil, é possível encontrar até mesmo uma boa parte das ofensas pessoais trocadas entre os candidatos.

Dentre essas obras de cunho jornalístico, pode ser mencionado $O$ Brasil vai às urnas: retrato da campanha presidencial, do jornalista Antônio de Pádua Gurgel em parceria com o cientista político David Fleischer. ${ }^{1}$ No primeiro capítulo, os autores procuram, à luz de alguns conceitos teóricos, dar uma explicação para a transição política brasileira da década de 1980 e destacam o continuísmo das estruturas política herdadas do regime militar. Nas outras partes do livro, no entanto, não há maiores preocupações com teoria ou método. Por essa razão, acreditamos que o maior mérito deste texto está na narrativa detalhada de alguns dos principais fatos relacionados à eleição de 1989, além de breves incursões em outros momentos da política brasileira daquela década.

A leitura dessa obra e a observação dos procedimentos que caracterizaram a sua elaboração permite-nos dizer que ela se assemelha à história imediata, praticada pelos jornalistas. Esse tipo de trabalho, como lembram Agnès Chauveau e Philippe Tétart, ${ }^{2}$ pode até tomar a forma de uma análise que, hierarquizando pela primeira vez as questões e os fatos, forne-

1 GURGEL, Antônio de Pádua; FLEISCHER, David. O Brasil vai às urnas: retrato da campanha presidencial. Brasília: Thesaurus, 1990. p. 29-38.

2 CHAUVEAU, Agnès; TÉTART, Philippe. Questões para a história do presente. In: CHAUVEAU, Agnès; TÉTART, Philippe (Orgs.). Questões para a história do presente. Bauru, SP: Edusc, 1999. p. 24-25. 
ce conjuntamente arquivos, depoimentos, pistas de pesquisa e esboços de interpretação. Apesar de manter um aspecto científico, no entanto, ela permanece uma matéria que ainda precisa passar por uma releitura ou análise mais aprofundada.

Ainda com relação ao jornalismo, pode ser destacada a obra de Mário Sérgio Conti intitulada Notícias do Planalto. ${ }^{3}$ Um dos objetivos do autor foi entender como os interesses políticos e econômicos entre o governo e a imprensa influenciaram a cobertura política da mídia na era Collor. Também pretende mostrar como são tomadas as decisões nos grandes jornais, nas revistas e nas emissoras de televisão do país, além da forma de atuação dos jornalistas e os laços que estabelecem com o poder político. Para quem estuda o período, o livro de Conti não deixa de ter importância; ele foi diretor de redação da Revista Veja entre 1991 e 1997 e, portanto, conhece muito bem os bastidores da grande imprensa brasileira. Apesar de, todavia, acrescentar detalhes importantes a respeito de alguns dos principais fatos noticiados no período, incluindo a campanha eleitoral de 1989, acreditamos que essa obra não pode ser considerada um estudo definitivo a respeito do envolvimento ilícito entre a grande imprensa e a política na época, como chegou a ser cogitado. Pensamos que em relação a essa questão muitos aspectos ainda precisam ser esclarecidos.

Em nossa opinião, um exemplo do que estamos dizendo pode ser observado na análise que Mário Sérgio Conti fez sobre a participação da Rede Globo de Televisão na cobertura da campanha eleitoral de 1989. Essa emissora, há várias décadas, vem exercendo uma grande influência na vida política brasileira, e foi decisiva na eleição presidencial de 1989 e de muitas outras. Seu diretor presidente, Roberto Marinho, durante algumas décadas foi um dos homens mais poderosos do país. ${ }^{4}$ Nas páginas do livro de Conti, no entanto, a nosso ver, isso não foi devidamente enfatizado. Mesmo um dos episódios que evidenciaram a participação antiética da Globo na eleição de 1989, a edição manipulada do último debate entre Lula e Collor

3 CONTI, Mário Sérgio. Notícias do Planalto: a imprensa e Fernando Collor. São Paulo: Cia. das Letras, 1999.

4 Basta lembrar que, no final do governo do Presidente José Sarney, em 1988, Sarney submeteu o nome do futuro Ministro da Economia, Mailson da Nóbrega, a uma espécie de entrevista com Roberto Marinho, antes de nomeá-lo para o Ministério da Fazenda. Sobre essa questão ver NOBLAT, Ricardo. Céu dos favoritos. Rio de Janeiro: Rio Fundo, 1990. p. 174-175. 
no Jornal Nacional da emissora, que favoreceu este último, também não mereceu uma análise adequada. O fato foi tratado por Conti como uma decisão tomada no segundo escalão da direção de jornalismo da Rede Globo, sem o conhecimento ou a aprovação de seu diretor-presidente. ${ }^{5}$ A esse respeito é suficiente dizer que outros estudos apontam Roberto Marinho como o principal responsável pela cobertura jornalística do jornal O Globo, bem como da sua emissora de televisão. ${ }^{6}$ Dessa forma, não é possível acreditar que um assunto daquela magnitude não tenha passado pelo conhecimento do presidente da Rede Globo, na época, que havia aderido publicamente à candidatura de Fernando Collor.

Já na área que se dedica mais à ciência da comunicação é possível encontrar trabalhos que procuram dar explicações mais aprofundadas sobre a eleição de 1989. É o caso do ensaio de Venício de Lima intitulado Televisão e política: hipótese sobre o primeiro turno da eleição presidencial de 1989. Trabalhando com as teorias da comunicação, que enfatizam o poder da mídia não só em termos de efeitos de curto prazo, mas de efeitos cognitivos de longo prazo, ele procura construir um modelo explicativo bastante interessante. $\mathrm{O}$ autor defende a hipótese de que a vitória de Collor na eleição presidencial brasileira de 1989 deve ser buscada no Cenário de Representação da Política ${ }^{7}$ construído pela televisão antes de junho daquele ano. Tal processo teria começado já em 1988 após a definição da duração do mandato de Sarney. Para confirmar a sua hipótese, analisa dados das pesquisas de opinião pública entre 14 de março e 14 de novembro de 1989,

5 CONTI, op. cit., p. 264-271.

6 Sobre esse assunto ver LIMA, Venício A. de. Televisão e política: hipótese sobre o 10 turno da eleição presidencial de 1989. In: Mídia: teoria e política. São Paulo: Fundação Perseu Abram, 2001. p. 213-249

7 A concepção de cenário de representação da política traz implícita a idéia de que os conteúdos políticos veiculados na mídia vão além dos períodos de eleição e dos horários políticos propriamente ditos. Não só durante as campanhas políticas, "mas também nos intervalos entre elas, a mídia fornece perspectivas, modela as imagens dos candidatos e dos partidos, ajuda a promover os temas sobre os quais versará a campanha e cria a atmosfera específica e as áreas de relevância que definem qualquer campanha eleitoral”. Além de estabelecer a temática (agenda, pauta) e os limites dentro dos quais as campanhas podem se desenrolar, a mídia transmite juízos de valores nas novelas, nos filmes, nas séries, nos telejornais, nos programas humorísticos, e acaba por condicionar/determinar as chances de um candidato, e faz com que seja mais ou menos adequado à era da videopolítica (LIMA, 2001, p. 220-222). Para uma discussão mais específica sobre o conceito de Cenário de Representação da Política, ver, do mesmo autor, o ensaio intitulado: Cenário de Representação da Política (CR-P), In: Mídia: teoria e política. São Paulo: Fundação Perseu Abram, 2001. 
nos quais constata que Collor teria vencido a eleição em junho de 1989, antes do início do horário eleitoral gratuito, quando atingiu $43 \%$ das intenções de votos. Teria vencido pois, embora esses números tenham registrado queda, ele não mais perderia o primeiro lugar a partir de então. O horário eleitoral gratuito, antes do primeiro turno da eleição, somente contribuiu para Brizola e Lula recuperarem o porcentual de intenções de votos que detinham em março de $1989 .{ }^{8}$

Ao contrário de Antônio de Pádua Gurgel, David Fleischer e de Mário Sérgio Conti, o texto de Lima propõe uma hipótese muito interessante para explicar a vitória de Fernando Collor de Mello na eleição presidencial brasileira de 1989, por intermédio do conceito de Cenário de Representação da Política. A nosso ver, o único ponto discutível nessa tese diz respeito aos problemas relacionados à recepção das mensagens. A bem da verdade, Lima não ignora essa questão, e lembra a audiência ativa e a resistência cultural. Também destaca que a construção de significados sempre se dará dentro de limites predeterminados, dialeticamente, em um processo de luta na construção do sentido hegemônico. Ele acredita, entretanto, que, no caso da relação comunicação e política, os resultados eleitorais são indicadores precisos do comportamento do eleitor, ou seja, da sua atividade como receptor e como construtor dos significados das mensagens. ${ }^{9}$ Mesmo tendo levantado essas questões, todavia, o autor não se aprofunda na análise dos problemas da recepção das mensagens. Evidentemente que esse não era o seu objetivo, e ele chega a admitir a necessidade de pesquisas específicas para avançar nesse terreno. Por essa razão, pensamos que a relação do Cenário de Representação da Política construído pela mídia e a estratégia de marketing de Collor com o resultado da eleição precisam ser mais discutidas. Em outras palavras, é necessário investigar mais as questões ligadas à recepção da mensagem para se saber como os eleitores receberam a imagem de Collor construída pela mídia, na época. ${ }^{10}$ Só o resultado da eleição, talvez, não seja suficiente para dar conta desta questão.

8 LIMA, op. cit., p. 214-221.

9 Ibid., p. 247-248.

10 É sempre bom lembrar que vários estudos têm apontado a complexidade a respeito da questão da recepção, com destaque à relativa autonomia das pessoas no consumo das mensagens. Sobre esta questão ver: MARTÍN-BARBERO, Jesús. Dos meios às mediações: comunicação, cultura e hegemonia. Rio de Janeiro: UFRJ, 1997; CERTEAU, Michel de. A invenção do cotidiano: 1. Arte de fazer. Petrópolis, Rio de Janeiro: Vozes, 1994. 
Dentre outros trabalhos importantes na área da comunicação, também pode ser lembrado o texto de Carly Aguiar a respeito do imaginário político das elites brasileiras estampado nos grandes jornais escritos da época. Como se sabe, a eleição presidencial de 1989 foi um momento privilegiado para se observar o arraigado conservadorismo da grande mídia do país. Essa postura se revelou não somente em relação às opções eleitorais, mas também no que diz respeito aos temas políticos, econômicos e sociais discutidos durante a campanha. Na imprensa escrita, tanto jornalistas como representantes das elites ${ }^{11}$ freqüentemente utilizaram um discurso que se estruturava, em termos de imaginário, no mito da conspiração, além de enfatizarem o perigo de o Brasil se tornar um país comunista ou socialista, caso as esquerdas vencessem a eleição. Em contrapartida, o mito do "salvador da pátria” foi encarnado por Fernando Collor de Mello, que, para essas pessoas, passou a simbolizar o bem contra o mal. ${ }^{12}$ Naquele contexto, como bem observou a autora, nenhum dos grandes jornais brasileiros apoiou 0 candidato do Partido dos Trabalhadores no segundo turno. O mesmo pode ser dito em relação às grandes redes de televisão, que, implícita ou explicitamente, apoiaram o candidato Fernando Collor de Mello.

No que se refere à Ciência Política, muitos trabalhos foram produzidos sobre a eleição de 1989 e, como não poderia deixar de ser, constituem referências obrigatórias para o estudo do tema. No conjunto, a maioria dessas obras procurou explicar a vitória de Fernando Collor de Mello para a Presidência da República em função dos fracassos da "Nova República”, iniciada em 1985, em atender aos anseios da população mais pobre do país. Basta lembrar que, em meados daquela década, a crise econômica se agravou e a inflação passou a atingir altos índices a partir de 1987. Muitos comentaristas acreditam que esse cenário é o principal responsável pelo profundo descontentamento da população em relação ao Governo Sarney, ao $\mathrm{PMDB} / \mathrm{PFL}$ e à maioria dos políticos profissionais. ${ }^{13}$ Acrescente-se que

11 Com o termo “elites”, estamos nos referindo a políticos, a empresários e a intelectuais em geral.

12 AGUIAR, Carly B. de. Imprensa e eleições 89: imagens e atores da política. Revista Comunicação \& Política, Rio de Janeiro, v. 1, n. 3, p. 179-194, abr./jul. 1995.

13 LAMOUNIER, Bolívar. Antecedentes, riscos e possibilidades do governo Collor. In: LAMOUNIER, Bolívar (Org.). De Geisel a Collor: o balanço da transição. São Paulo: Sumaré / Idesp, 1990. p. 13-35; SALLUM JR., Brasilio; GRAEFF, Eduardo P.; LIMA, Elisabeth Gomes de. Eleições presidenciais e crise do sistema partidário. Revista Lua Nova, São Paulo, n. 20, p. 69-87, maio 1990. 
vários trabalhos apontaram a fragilidade dos partidos políticos na época como um dos elementos que ajudam a entender a ascensão de Collor. ${ }^{14}$ Outras análises destacaram a competência/capacidade administrativa, a questão da moralização da política e a imagem de jovem que o candidato procurou construir, por intermédio de seu marketing político, como uma das razões de voto de seus eleitores. ${ }^{15}$

Apesar de existirem semelhanças de enfoques em muitas dessas discussões, é possível observar diferenças em algumas linhas de argumentação sobre as razões de votos dos eleitores que participaram da disputa eleitoral de 1989. A nosso ver, entre os ensaios mais interessantes que analisaram a eleição e as razões de voto, alguns apontaram a formação de uma nova cultura política no país, além de destacarem que a ideologia foi um grande preditor de voto no segundo turno da eleição de 1989. Outros enfatizam a avaliação que o eleitor fez do desempenho do governante em exercício e de certos atributos pessoais dos candidatos como motivos do voto. Na mesma linha, apareceu um trabalho defendendo que a principal razão do voto estava relacionada à expectativa de uma maior capacidade de desempenho do político escolhido. ${ }^{16}$ Já para os analistas que exploraram o campo do imaginário, a ascensão de Collor foi tecida sobre o mito do herói salvador, fundamentada na imagem do novo, de um jeito novo de fazer política. ${ }^{17}$ Da mesma forma, a imagem do candidato também foi associada à figura de um Indiana Jones, “aventureiro solitário, sem raízes, sem compromissos, lutando contra as forças do templo da perdição". ${ }^{18}$

Certamente que essas teses não esgotam todas as explicações que foram propostas para os resultados da eleição de 1989, mas acreditamos

14 LIMA JR., Olavo Brasil de. Democracia e instituições políticas no Brasil dos anos 80. São Paulo: Edições Loyola, 1993; DINIZ, Eli. Crise política, eleições e dinâmica partidária no Brasil: um balanço histórico. DADOS - Revista de Ciências Sociais, Rio de Janeiro, v. 32, n. 3, p. 323-340, 1989; LAVAREDA, Antônio. Governos, partidos e eleições segundo a opinião pública: o Brasil de 1989 comparado ao de 1964. DADOS - Revista de Ciências Sociais, Rio de Janeiro, v. 32, n. 3, p. 341-362, 1989.

15 KINZO, Maria D’Alva Gil. A eleição presidencial de 1989: o comportamento eleitoral em uma cidade brasileira. DADOS - Revista de Ciências Sociais, Rio de Janeiro, v. 35, n. 1, p. 49-65, 1992.

16 ALBUQUERQUE, J. A. Guilhon. Identidade, oposição e pragmatismo: uma teoria política do voto. Revista Lua Nova, n. 26, p. 53-79, 1992.

17 MENDONÇA, Kátia Marly Leite. A salvação pelo espetáculo: o mito político do herói no “Brasil novo”. São Paulo, 1997. Tese (Doutorado em Ciências Políticas) - FFLCH-USP/ SP.

18 CARVALHO, José Murilo de. Eleição em tempo de cólera. Cadernos de Conjuntura, Rio de Janeiro, n. 20, p. 10-15, jul. 1989. 
que elas representam um painel significativo das discussões que foram realizadas sobre o tema. De nossa parte, em linhas gerais, concordamos com as principais conclusões desses trabalhos; por esta razão, não pretendemos, e nem temos espaço nos limites deste artigo para aprofundar a discussão de todos esses eixos temáticos. Assim sendo, na seqüência, vamos dialogar com três cientistas políticos que defenderam algumas das teses mais interessantes nesse debate, apontando, quando for o caso, as nossas discordâncias.

José Álvaro Moisés, por exemplo, estudou a eleição de 1989 e levantou alguns elementos para se pensar o comportamento do eleitorado naquele momento. Contrariando explicações que detectaram traços de desencanto com a democracia e a política em 1989, Moisés vê naquele pleito fortes indícios do surgimento de uma nova cultura política no Brasil. Compulsando os seus dados, vê-se que ele observou um aumento da participação eleitoral, que se expressou na queda dos índices de abstenção e de votos brancos e nulos, configurando, portanto, um maior comparecimento às urnas. Tais evidências foram interpretadas como indícios da consolidação de valores básicos em relação à vida política e indicadores da adesão dos cidadãos ao novo regime democrático do país. O autor afirma, ainda, que outras pesquisas de 1989 revelaram que dois terços dos eleitores brasileiros continuariam votando mesmo que o voto não fosse obrigatório. Eles também demonstraram uma progressiva adesão à democracia em contraposição à aceitação da ditadura ou de uma posição de indiferença. ${ }^{19}$

De um modo geral, concordamos com os argumentos de José Álvaro Moisés para explicar as razões da vitória de Fernando Collor de Mello, em 1989, em termos do significado oposicionista de sua candidatura em relação ao governo Sarney. Tal imagem foi completada pelo eficiente marketing político com o slogan do “caçador de Marajás”, pelas acusações de Collor de que Lula representaria uma ameaça aos direitos de propriedade, além de associar o programa de governo do candidato do PT ao estatismo, em um momento de crise no socialismo do Leste europeu. Temos, todavia, dúvidas a respeito de sua tese sobre a formação de uma nova cultura política entre os brasileiros. Com base nessa idéia, Moisés afirma que em 1989,

19 MOISÉS, José Álvaro. Eleições, participação e cultura política: mudanças e continuidade. Revista Lua Nova. São Paulo, n. 22, p. 133-187, dez. 1990. 
além do voto de rejeição aos governos considerados incapazes, os eleitores votaram, também, “contra o arcaísmo da tradição política brasileira, particularmente, as práticas de corrupção, favoritismo e privatismo”. ${ }^{20}$ Não há dúvidas de que, em 1989, uma parte do eleitorado votou contra essas questões; mas, mesmo assim, ao menos para uma grande parcela dos votantes, não acreditamos que esse comportamento representava uma nova cultura política com as características apontadas pelo autor, em que se destacava uma progressiva adesão à democracia. ${ }^{21}$

Talvez o otimismo de Moisés em relação à formação de uma nova cultura política no Brasil possa ser compreendido se considerarmos que ele escreveu, em 1990, na cidade de São Paulo. Nessa época, fazia pouco tempo que havíamos saído de uma ditadura militar que durou longos vinte e um anos, e tínhamos percorrido uma década, a de 1980, bastante agitada politicamente, na qual o povo, em alguns momentos, foi embalado pelo sonho de mudanças de dias melhores. Em que pese o desencanto que logo surgiu com os fracassos do primeiro governo civil da "Nova República”, no final da década, a possibilidade de eleger um presidente da República, após quase trinta anos, trouxe de volta a esperança de mudanças para muitos brasileiros. A nosso ver, os resultados das pesquisas de opinião de Moisés devem ser entendidos dentro desse contexto que, provavelmente, influenciou as respostas dos eleitores sobre a democracia e a participação política na época. Acreditamos que essa pode ser uma explicação para entender a crença do autor em relação ao interesse dos brasileiros pela política, pela democracia e mesmo pelos partidos políticos.

Na mesma linha de argumentação, podemos situar a tese de doutorado de André Singer. Nela, o autor procurou demonstrar que a identificação ideológica foi uma das principais preditoras do voto no segundo turno

20 MOISÉS, op. cit., p. 133-134.

21 No ano de 2000, por exemplo, o Datafolha realizou uma pesquisa de opinião pública e revelou que apenas $47 \%$ dos brasileiros eram favoráveis à democracia; se somados os que aceitavam uma ditadura em certas circunstâncias (18\%) aos que responderam que tanto faz (29\%), verifica-se um empate entre as pessoas que preferiam uma democracia e aquelas que aceitariam um regime autoritário. Em fevereiro de 1992, esses números já haviam sido piores: somente $42 \%$ dos entrevistados pelo Datafolha preferiam a democracia. ROSSI, Clóvis. 29\% não dão importância à democracia. Folha de São Paulo, São Paulo, 16 jul. 2000. (Caderno especial sobre eleições intitulado Retrato do eleitor). Se observamos que em março de 1990 o número de eleitores favoráveis à democracia havia atingido 54,7\%, fica evidente, portanto, que houve queda nessa preferência. 
da eleição presidencial de 1989 e na eleição de 1994. Na sua opinião, a redemocratização produziu um aumento da proporção de eleitores brasileiros capazes de reconhecer as categorias de esquerda e de direita. Entre 1989 e 1994, tal processo havia atingido os índices dos países desenvolvidos. Como prova da coerência ideológica do voto nessas eleições presidenciais, Singer afirma que 74\% dos eleitores de Collor, 65\% dos de Maluf e $65 \%$ dos de Covas escolheram Fernando Henrique em 1994. A seu ver, eles sabiam localizar os partidos na escala esquerda-direita com a mesma classificação da ciência política. Assim, todos os dados colhidos nas pesquisas de opinião, desde 1990, teriam evidenciado que os votantes sabiam usar o critério ideológico para distinguir os partidos políticos. ${ }^{22}$

No entanto, quando Singer analisa os dados das pesquisas de opinião pública intituladas Cultura Política 1989/1990, que compõem a sua documentação básica, afirma que mais de $60 \%$ dos eleitores não sabiam dizer o significado de esquerda e de direita. Mesmo aceitando como corretas as respostas sobre a esquerda ser contra o governo e a direita a favor, elas não passaram de $20 \%$ da amostra. A explicação de Singer para essa capacidade do eleitor de se posicionar em um espectro esquerda-direita para orientar a decisão do voto, sem saber o significado dessas terminologias, refere-se a um conhecimento intuitivo, a um sentimento do que significam as posições ideológicas. Tal intuição permitiria ao eleitor colocar-se na escala, em uma posição que está de acordo com as suas inclinações, sem que necessariamente soubesse verbalizá-la. Esse sentimento o conduziria a situar os candidatos e os partidos na referida escala e votar coerentemente. ${ }^{23}$ Certamente que os eleitores são capazes de intuir, mas acreditamos que isso não nos autoriza a afirmar que eles têm percepções do que seja esquerda ou direita suficientes para uma participação em um processo eleitoral baseado em ideologia. Ao menos, não constatamos isso na nossa pesquisa de doutorado referente à eleição de 1989 em Maringá. Até porque, na atualidade, mesmo entre os intelectuais, não existe um sólido consenso sobre a definição dessas categorias; então como esperar que o cidadão comum oriente a sua participação nas urnas com base nelas?

22 SINGER, André Vitor. Identificação ideológica e voto no Brasil: o caso das eleições presidenciais de 1989 e 1994. São Paulo, 1998. Tese (Doutorado). Universidade de São Paulo - USP. p. 136148.

23 Ibid., p. 146-149. 
Nesse sentido, estamos diante de uma tese que utiliza uma argumentação, no mínimo, muito polêmica para defender a idéia de que a ideologia foi a principal preditora do voto nas eleições presidenciais de 1989 e 1994. Pensamos que um dos maiores problemas dessa discussão é afirmar, como faz Singer, que os eleitores sabem localizar os partidos na escala esquerda-direita com a mesma classificação da Ciência Política. Isso significa atribuir aos sujeitos uma forma de pensar própria dessa disciplina, que, com certeza, a maioria absoluta dos homens e mulheres das camadas populares não tem. Como argumenta Patrick Champagne, o mundo político não é apreendido por todos a partir das categorias de percepções peculiares à política; pode haver política que venha a se exprimir por palavras diferentes daquelas utilizadas pelos seus profissionais. ${ }^{24}$ Não podemos, portanto, atribuir a todos os esquemas de pensamento desse campo.

Nesse debate, as proposições do cientista político Yan de Souza são mais aceitáveis. Ele concorda que parece ter havido uma correlação moderada entre a imagem política dos candidatos, relacionada à polaridade esquerda-direita, e a influência na decisão do voto. Mas, na seqüência, pondera que essa relação entre o posicionamento na escala esquerda-direita e o voto foi mais relevante para os eleitores de nível superior, e um preditor de voto relativamente fraco para a maioria dos eleitores de baixa escolaridade. Na opinião do autor, a avaliação predominantemente negativa do governo Sarney teve peso importante no resultado do primeiro turno da eleição; da mesma forma, a avaliação que os eleitores fizeram sobre os atributos pessoais dos candidatos, relacionados à experiência e à competência técnica para governar, foi um dos elementos centrais para a decisão de voto na eleição de $1989 .{ }^{25}$

No campo da sociologia, em que pese o menor número de trabalhos que encontramos sobre o tema, a obra de Francisco de Oliveira também trouxe uma importante contribuição para se entender a transição política brasileira da década de 1980, marcada por uma persistente crise econômica e um crescente descontentamento com o governo Sarney, após o fracasso do Plano Cruzado em 1986. Ao que se sabe, essas questões influencia-

24 CHAMPAGNE, Patrick. Formar a opinião: o novo jogo político. Petrópolis, Rio de Janeiro: Vozes, 1996. p. 36.

25 CARREIRÃO, Yan de Souza. A decisão do voto nas eleições presidenciais brasileiras. Florianópolis: UFSC; Rio de Janeiro: FGV, 2002. p. 80-120. 
ram os rumos da votação em 1989. Como observa Oliveira, em termos de desempenho econômico, a década de 1980 foi considerada perdida, e registrou taxa negativa de crescimento de - 4,3\% já em 1981. Assim, a crise econômica na Nova República assumiu o caráter de "à beira do abismo", intermitentemente com a inflação chegando aos $80 \%$ ao mês em março de 1990. Tal fato afetou a acumulação, e deteriorou todos os serviços públicos. A Nova República, além de herdar alguns desses elementos e conteúdos críticos, acrescentou uma crise de credibilidade pública do Estado, da política e dos políticos sem paralelo na moderna política brasileira. Neste sentido, ela deslocou o centro de gravidade da crise econômica para uma crise geral do Estado, do governo, e das instituições. Para Oliveira, na medida em que o novo regime democrático não solucionou os problemas econômicos, ele potenciou o descrédito na política. A seu ver, foi esse o pavimento sobre o qual caminhou o "messias de Alagoas", personificado, na época, por Fernando Collor de Mello. ${ }^{26}$

Na mesma linha de argumentação, Muszynski também lembra que o discurso de superação do regime militar associava o advento da democracia à implementação de medidas de impacto capazes de sanar, em um curto espaço de tempo, os graves problemas econômicos da maioria da população. O Plano Cruzado de 1986, plano econômico que prometia concretizar a aliança entre mudança econômica e política, levou as expectativas ao auge. Mas a decepção que logo se seguiu contribuiu para reavivar a imagem de inoperância dos governantes e das instituições públicas, além de acentuar a hostilidade da população contra eles, os culpados pelo sofrimento do povo. Mais uma vez a esperança se transferiu para a futura sucessão presidencial. ${ }^{27}$ Podemos dizer, portanto, que os argumentos de Oliveira e Muszynski fazem parte de uma das principais correntes de explicação para se entender o contexto histórico que certamente influenciou os resultados da eleição presidencial brasileira de 1989; trata-se de um período marcado por uma grande frustração das camadas populares com os desdobramentos da abertura democrática, iniciada em meados da década de 1980, que não se traduziu em melhoria de vida para a população mais pobre do país.

26 OLIVEIRA, Francisco de. Collor, a falsificação da ira. Rio de Janeiro: Imago, 1992. p.

$31-32$.

27 MUSZYNSKI, Judith. Cultura política, democracia e eleições. In: LAMOUNIER, Bolívar et al. Cem anos de eleições presidenciais. São Paulo: Idesp, 1990. p. 22-23. 
Lendo uma boa parte da literatura sobre o tema, percebemos a existência de um consenso na maioria dos estudos que discutiram a eleição presidencial brasileira de 1989 quanto à definição do cenário político, econômico e social em que transcorreu a campanha eleitoral. De um modo geral, o país atravessava uma grave crise econômica, com a inflação chegando a 80\% ao mês, após vários programas de estabilização da economia. Existia uma insatisfação muito grande, por parte da população, com o governo Sarney, o PMDB e com a maioria dos políticos. Estes eram considerados desonestos, corruptos, que só defendiam os seus próprios interesses, dos parentes e dos amigos. Aliás, a corrupção, é bom que se diga, era considerada um dos principais problemas do Brasil, na época. Da mesma forma, a maioria das pessoas não acreditava nas instituições, particularmente no Congresso e nos partidos; mesmo o Estado havia perdido credibilidade, e os funcionários públicos, com raras exceções, eram considerados marajás. Com isso, os sucessivos fracassos da "Nova República”28 - capitaneada por Sarney e Ulisses Guimarães - em resolver os problemas básicos da população pobre do país fizeram com que todo o manancial de esperanças depositado por essa gente no processo de transição política do Brasil se transformasse em uma frustração muito grande com os políticos. Como observaram Sallum Jr. e Graeff, ${ }^{29}$ foi nesse barro que se moldaram as imagens dos candidatos que se destacaram nas preferências dos eleitores no primeiro turno. Podemos acrescentar que essa também parece ter sido a orientação geral para a maioria dos votantes no segundo turno; ou seja, todos os que, de alguma forma, foram identificados como responsáveis pela situação em que o país se encontrava foram reprovados nas urnas daquele final de década.

De outra parte, nessas discussões, a Antropologia explorou uma perspectiva diferente, mas muito importante para quem quer estudar as elei-

28 Nova República foi o nome dado ao processo de redemocratização do país, com o fim da ditadura militar e a passagem do poder aos civis. Tancredo Neves, do PMDB, foi eleito Presidente da República por um Colégio Eleitoral em 1985, tendo como vice José Sarney, egresso do PDS, partido que dava sustentação ao regime militar. Na verdade, essa transição foi feita sob a égide de um acordo político conservador, que na essência mascarava o continuísmo das estruturas políticas de mando, sob a capa de um verniz democrático. Para piorar a situação, Tancredo Neves, em quem a população parecia depositar confiança e esperança, faleceu antes de tomar posse no cargo. Naquelas circunstâncias, Sarney assumiu a Presidência da República sem a credibilidade política necessária para governar a nação.

29 SALLUM JR., Brasilio; GRAEFF, Eduardo P.; LIMA, Elisabeth Gomes de. Eleições presidenciais e crise do sistema partidário. Revista Lua Nova, São Paulo, n. 20, p. 69-87, maio 1990. 
ções, quer seja no final da década de 1980 ou em qualquer outra época. Contrariamente a uma boa parcela das interpretações dos processos eleitorais que parecem limitar o alcance da política ao domínio mais institucionalizado do Estado e dos partidos, a abordagem antropológica está mais interessada em desvendar o comportamento do eleitor no momento do voto. Nas palavras de Márcio Goldman e Ronaldo Sant'Anna, "trata-se de reconhecer que o voto está envolvido em uma rede de forças que transcende em muito o domínio do que se convencionou denominar política”. ${ }^{30} \mathrm{Na}$ opinião dos autores, existe uma multiplicidade de motivações implicadas no ato de votar, nas quais a subjetividade também deve ser considerada. ${ }^{31}$ Assim, pode-se dizer que esta reflexão corrobora outras análises que também têm destacado que o voto não tem apenas uma dimensão racional. A nosso ver, a principal contribuição deste trabalho para o estudo do processo eleitoral está em apontar que existem diferentes modos de se pensar e de se viver o político, e essas concepções informam a prática e as demais representações dos agentes sociais a respeito do campo político.

Na mesma perspectiva, Nara Magalhães também investigou a relação das camadas populares com a política em períodos eleitorais. O seu trabalho nasceu do estudo das eleições para prefeito de Porto Alegre, em 1986 e 1992, e da eleição presidencial brasileira de 1989 na mesma cidade. Pesquisando em alguns bairros da capital gaúcha, a autora procurou entender o significado que os agentes sociais têm da política e das relações de poder dentro do seu sistema cultural. Em outras palavras, é dentro da visão de mundo do grupo que Magalhães buscou apreender a representação que as pessoas têm da política e do poder. Nessa abordagem antropológica inspirada em Geertz, a autora investigava o porquê da vitória de determinado candidato e descobriu uma lógica da maneira pela qual os entrevistados encaram a política, em especial quando votam. Na sua opinião, tal lógica

30 GOLDMAN, Marcio; SANT’ANNA, Ronaldo dos Santos. Elementos para uma análise antropológica do voto. In: PALMEIRA, Moacir; GOLDMAN, Marcio (Coords.). Antropologia, voto e representação política. Rio de Janeiro: Contra Capa Livraria, 1996. p. 22-31.

31 A bem da verdade, essa reflexão antropológica sobre o voto foi elaborada mais em função da eleição presidencial brasileira de 1994; seus autores, todavia, acabam analisando o comportamento de alguns eleitores de Collor na eleição presidencial de 1989. Ademais, acreditamos que esse trabalho aponta uma perspectiva importante para analisar o comportamento dos eleitores em qualquer eleição. 
está relacionada a um imaginário sobre a arte de governar que leva as pessoas a agir de maneira singular. ${ }^{32}$

Acreditamos que uma das constatações mais importantes do trabalho de Magalhães diz respeito ao fato de que o voto não é individual, está respaldado pelo coletivo: vizinhança, parentesco e afinidades. ${ }^{33}$ Desse modo, talvez seja importante observar que em nossa tese de doutorado sobre a eleição presidencial de 1989, em Maringá (PR), também chegamos a uma conclusão semelhante. Na verdade, nem sempre os depoentes admitiam que levavam em consideração as opiniões das outras pessoas na hora de escolher o candidato. Mas, quando analisávamos as falas deles ficava evidente que os amigos, os vizinhos e os parentes - às vezes chamados de o pessoal, a turma - constituíam uma fonte de informação e troca de experiências utilizada no momento do voto. ${ }^{34}$

Destaque-se também, nos estudos da Antropologia, o trabalho de Gilberto Velho, que explorou um outro aspecto da dimensão simbólica para explicar a vitória de Fernando Collor. Na sua perspectiva, encontramos na história do Brasil uma longa galeria de personagens que desembocam na figura do presidente eleito em 1989. "São os heróis salvadores, tocados por carisma, que mobilizaram, cada qual em circunstâncias específicas, a paixão e admiração de vastos setores da sociedade nacional”. Tais personagens seriam atualizações de crenças e de valores associados ao milenarismo e ao messianismo, que têm, no mundo luso-brasileiro, o sebastianismo como expressão da crença em indivíduos excepcionais, destinados a redimir e a salvar o povo de opressores, da injustiça e dos abusos. Velho acredita que tanto a figura do jovem rei pode ser aproximada à de São Sebastião e de São Jorge, presentes na religiosidade popular brasileira, como as histórias e as lendas de lutas contra os mouros aproximam o personagem e os santos citados; da mesma forma, prossegue, mouros e marajás também podem ser aproximados no imaginário popular. $\mathrm{O}$ autor termina esse interessante percurso pelo imaginário argumentando que, em época de crises, de fome e de

32 MAGALHÃES, Nara Maria Emanuelli. O povo sabe votar: uma visão antropológica. Petrópolis, RJ: Vozes, 1998. p. 13-20; 123.

33 Ibid., p. 83-85.

34 NASCIMENTO, Luiz Miguel do. Olhar cotidiano sobre a política: a eleição presidencial de 1989 e a eleição municipal de 2000 em Maringá. São Paulo, 2003. Tese (Doutorado em História Social). Programa de Estudos Pós-Graduados em História da Pontifícia Universidade Católica de São Paulo. p. 223227. 
dificuldades em geral, ressurge ciclicamente a esperança em uma terra prometida, abençoada, onde correrão o leite e o mel e a justiça será instaurada. Collor de Mello, a seu ver, teria se encaixado como uma luva dentro desse universo de heróis salvadores. ${ }^{35}$ Concorde-se ou não com essa tese, a grande verdade é que o imaginário já não pode mais ser ignorado por quem estuda a política, particularmente as eleições. Desse modo, pensamos que esse é mais um dos elementos válidos para ajudar a entender a vitória de Fernando Collor em 1989.

Ao que sabemos, de uma maneira geral, é a partir do conhecimento da cultura dos sujeitos que os antropólogos procuram apreender os significados que atribuem às questões que afetam as suas vidas. Assim sendo, as reflexões da disciplina são muito valiosas para o estudo do comportamento eleitoral, que, sem dúvida nenhuma, não pode mais ser explicado apenas em termos de desinformação, de alienação e de manipulação do eleitor, seja pelos políticos, pela mídia, ou pelas classes dominantes. Naturalmente que, ao se trabalhar com a dimensão cultural da vida social, não se deve despolitizar o conceito de ideologia e utilizá-lo apenas como sinônimo de sistemas de idéias e visão de mundo, sem levar em consideração a problemática da luta de classes. Com essa observação, entretanto, não estamos querendo dizer que a participação política deva ser pensada somente em termos de classes sociais; mas é necessário que o grupo compartilhe ao menos de uma experiência comum para se falar que possui uma mesma representação a respeito da política ou de qualquer outra dimensão da vida em sociedade. Em outras palavras, não é possível dizer que pessoas de condições sociais diferentes compartilhem de uma mesma concepção sobre a política. ${ }^{36}$ De qualquer forma, pensamos que não é mais possível estudar a política, particularmente as eleições, sem as contribuições dos estudos sobre a cultura.

Nesse sentido, gostaríamos de destacar aquilo que para nós é o aspecto mais importante do exercício que tentamos fazer até aqui. Trata-se de constatar que mesmo uma breve incursão como esta aos debates que as outras ciências sociais realizaram sobre a política brasileira na década de

35 VELHO, Gilberto. A vitória de Collor: uma análise antropológica. Revista Novos Estudos, São Paulo, n. 26, p. 44-47, mar. 1990.

36 Para uma maior discussão sobre essa questão ver RANCIÈRE, Jacques. O desentendimento: política e filosofia. São Paulo: Ed. 34, 1996. 
1980, em particular a eleição presidencial 1989, reforça a certeza da necessidade do diálogo interdisciplinar para abordar, de forma mais abrangente, o estudo da política. Como se vê, todas as disciplinas trouxeram contribuições para o entendimento da temática. Mesmo o jornalismo, que no geral não realiza análises em profundidade, registra um manancial de informações, de fatos e acontecimentos indispensáveis para quem pesquisa a história política. A área da comunicação, por exemplo, elaborou o conceito de Cenário de Representação da Política, muito importante para percebermos que as campanhas políticas transcendem o horário eleitoral gratuito e podem ser vistas não só nos jornais e nos telejornais, mas em novelas, em programas de auditório e em muitos outros momentos em que a mídia constrói os temas, os problemas, a imagem do candidato ideal e a visão de política que o poder hegemônico quer impor à sociedade. Esse conceito abre possibilidades muito promissoras para a análise das campanhas eleitorais.

Já em relação aos trabalhos de Ciência Política que lemos, pode-se dizer que, quando eles utilizam apenas as pesquisas quantitativas ${ }^{37}$ de opinião pública como dados empíricos, algumas vezes deixam a desejar em suas análises. É sabido que essa metodologia de pesquisa não consegue atingir um conhecimento mais profundo sobre o que pensam as pessoas de uma sociedade em relação a um tema em determinada época. O máximo que faz é coletar uma opinião subliminar, efêmera, inarticulada, e apresentar o resultado dessa somatória como a opinião de todo um povo. Assim, muitas vezes, tudo o que essas pesquisas conseguem é produzir um efeito de crença que se confirma porque os agentes do campo político acreditam nessa previsão e agem em conformidade com ela. ${ }^{38}$ Mesmo assim, nem é preciso dizer que não mais é possível estudar a política sem as contribuições da Ciência Política. Da mesma forma, a Antropologia, ao que nos parece, tornou-se indispensável para o estudo da participação das camadas populares na política. A sua ênfase na dimensão cultural da vida social nos

37 Não que devemos desprezar a estatística, mas, como lembra Michel de Certeau, ela capta o homogêneo e não consegue apreender o heterogêneo, o diferente. CERTEAU, op. cit., p. 45-46.

38 Sobre as limitações metodológicas das pesquisas de opinião pública, ver BOURDIEU, Pierre. Os doxósofos. In: THIOLLENTE, Michel J. M. (Org.). Crítica metodológica, investigação social \& enquete operária. 5. ed. São Paulo: Polis, 1987. p. 153-167. E, do mesmo autor, A opinião pública não existe. In: THIOLLENTE, Michel J. M. (Org.). Crítica metodológica, investigação social \& enquete operária. 5. ed. São Paulo: Polis, 1987. p. 137-151. 
ajuda a apreender os significados atribuídos pelas pessoas aos problemas que afetam as suas vidas; com isso, ela nos permite estudar a política para além dos conceitos racionais do pensamento letrado e procurar conhecer a percepção dos homens comuns sobre a arte de governar a pólis. Em outras palavras, é a partir dos valores da cultura do grupo que devemos procurar entender como o significado da política é apropriado pelas pessoas de determinada coletividade.

Posto isso, doravante vamos fazer algumas considerações sobre a História e as suas possibilidades de estudar o tempo presente. Há que se dizer, antes de prosseguir, que praticamente não existem pesquisas na disciplina relativas à eleição presidencial de 1989, e mesmo a outros momentos da década de 1980. Como já dissemos anteriormente, até onde sabemos, raros são os historiadores que estudaram essa temática no período. Assim sendo, mais do que discutir as contribuições que a História trouxe para o estudo da política na década de 1980, vamos propor duas questões para a reflexão sobre a sua ausência nesse debate. Diga-se de passagem que não pretendemos fazer nenhuma demonstração cabal a respeito dessas questões, mas apenas destacar que elas podem ajudar a entender algumas das razões pelas quais ainda existem poucas pesquisas em História relacionadas ao nosso tempo presente, em particular se considerarmos as duas últimas década do século XX.

É sabido que os praticantes da nossa profissão, em todo o mundo, com raras exceções, durante muito tempo resistiram a estudar os períodos mais próximos ou a história do tempo presente, na terminologia dos franceses. Nas últimas décadas do século XX, essas resistências começaram a diminuir, ao menos na França. No Brasil, entretanto, esses períodos de tempo mais recentes, sobretudo os anos 1980, quase não têm merecido a atenção dos historiadores; poucos são aqueles que se atrevem a pesquisá-los. A nosso ver, muitos historiadores ainda continuam observando um longo recuo temporal para estudar um fato histórico. Certamente que a mera utilização desse procedimento não é suficiente para qualificar quem quer que seja de positivista, mesmo porque existem muitas razões para a escolha de um recorte cronológico de pesquisa. Deve ser observado, todavia, que a necessidade de um longo recuo temporal para se estudar um objeto é um dos postulados da escola historiográfica que ficou conhecida como positivista. Nesse sentido, pensamos que, talvez, a influência dessa tradição acadêmica ajude a esclarecer a pouca importância que o nosso campo tem dado para 
os estudos dos anos 1980, em particular para a história política desse período, que, como já dissemos, ainda continua a ser uma seara mais visitada pelas outras áreas das ciências humanas.

Outra hipótese para explicar essa postura talvez esteja relacionada aos problemas que surgem quando se investiga o presente, a partir dos pressupostos da nossa disciplina. Os estudiosos da história do tempo presente têm destacado que essas dificuldades não dizem respeito à existência social ou científica dessa história mas ao seu próprio funcionamento, relacionado à atuação do historiador, que, ultimamente, reconhece o seu pertencimento à história. Assim sendo, além de outros fatores que poderiam ser discutidos a respeito dessa prática historiográfica, permanece o fato de que a observação da relação física entre o historiador, o seu tema e o seu tempo mostra que a definição de história do presente passa principalmente pela referência a uma nova relação entre o cientista e o seu campo de investigação. Em outras palavras, em vez de um longo distanciamento temporal proposto pela história tradicional para se estudar um acontecimento, os historiadores do presente postulam que é indispensável refletir sobre a presença do historiador em seu tema - presença direta ou indireta no tempo, presenças intelectual, moral, filosófica, psicológica, e até mesmo física. ${ }^{39}$

Ademais, como lembra Jean-Pierre Rioux, o argumento da falta de um recuo temporal para se estudar um acontecimento recente não se sustenta, pois é o próprio historiador, munido de uma metodologia científica de trabalho, que cria o famoso recuo. Na sua opinião, em última análise, a construção do relato histórico acaba hierarquizando os fatos a serem estudados. ${ }^{40}$ Devemos lembrar, todavia, que, do ponto de vista prático, em relação a alguns temas do tempo presente, o maior problema para o historiador são as fontes que, por muitas razões, nem sempre estão disponíveis. De qualquer forma, a nosso ver, nenhum desafio deve justificar o abandono do território do presente pelo historiador. Até porque, se concordarmos com a afirmação de Marc Bloch: "ocorre de, em uma linha dada, o conhecimento do presente ser diretamente ainda mais importante para a compreensão do passado". ${ }^{41}$

39 CHAUVEAU, Agnès; TÉTART, Philippe, op. cit., p. 28-31.

40 RIOUX, Jean-Pierre. Pode-se fazer uma história do presente? In: CHAUVEAU, Agnès; TÉTART, Philippe (Orgs.). Questões para a história do presente. Bauru, SP: Edusc, 1999. p. 46-47.

41 BLOCH, Marc Leopold Benjamin. Apologia da história, ou, O ofício de historiador. Rio de Janeiro: Jorge Zahar, 2001. p. 66-67. 
Na mesma linha de argumentação, Lucien Febvre há muito tempo já havia dito que a História era ciência do passado e do presente. Mesmo advertindo contra a ênfase no tempo curto, Fernand Braudel também observou que, por ser a dialética da duração, a História é explicação do social em toda a sua realidade, incluindo a atualidade. Na sua perspectiva, para o investigador chegar às tramas finas das estruturas do tempo presente, ele deveria formular hipóteses e explicações, e recusar o real tal como é percebido, como um dado, para melhor dominá-lo. ${ }^{42}$ Em outras palavras, o autor recomendava que o historiador sempre deveria colocar os acontecimentos, ou objetos de sua investigação, na perspectiva de uma longa dimensão temporal - a seu ver, a garantia mais segura de se entender a realidade, incluindo o presente.

A propósito, Braudel, quando discutiu a importância das durações ou temporalidades para a História, enfatizou que a longa duração parecia ser um dos caminhos mais úteis para uma aproximação com as ciências sociais. Preocupado com essa questão, o autor também argumentou que a duração social, esses tempos múltiplos e contraditórios da vida dos homens, não é apenas substância do passado, mas também o estofo da vida social atual. ${ }^{43}$ Pensamos que o grande mérito desta proposição, independentemente das controvérsias que ela possa suscitar, está em nos lembrar que uma das diferenças fundamentais entre a História e as outras ciências sociais reside na maior preocupação que o historiador deve ter com o tempo, ou a duração dos processos sócio-históricos, além das suas transformações.

Tendo em mente essas questões, só nos resta apontar uma das contribuições que a História pode trazer para o estudo da política no tempo presente, ou nos anos 1980, como é o nosso caso. Nunca é demais destacar que a disciplina se caracteriza pela discussão de alguns elementos muito importantes para o estudo dos homens em sociedade. Trata-se, como se pode observar na argumentação de Hobsbawm, da sua preocupação com as transformações, com as diferenças sociais, ou com o registro de vidas e eventos específicos e irrepetíveis. ${ }^{44}$ Além disso, enfatize-se a preocupação

42 BRAUDEL, Fernand. História e ciências sociais. A longa duração. In: Escritos sobre a história. 2. ed. São Paulo: Perspectiva, 1992. p. 56-59.

43 Ibid., p. 43-75.

44 HOBSBAWM, Eric J. O que a História tem a dizer-nos sobre a sociedade contemporânea? In: Sobre História. São Paulo: Cia. das Letras, 1998. p. 41-43. 
da História com a dimensão temporal, ou as temporalidades da vida dos homens. O tempo da História, para lembramos uma vez mais Marc Bloch, é o plasma em que se engastam os fenômenos, e lugar de sua inteligibilidade. Para o autor, a categoria da duração é a atmosfera em que respira o pensamento do historiador. ${ }^{45}$ Naturalmente que as outras áreas do conhecimento não ignoram essas questões, mas para nós elas são essenciais. Formam, por assim dizer, os elementos que compõem a identidade da nossa disciplina e a qualificam para ajudar a entender muitas questões da vida em sociedade.

O ofício do historiador, como se pode ver, tem nas transformações uma das suas preocupações básicas; mas as permanências, ou aquilo que muda mais lentamente, merecem, igualmente, a sua atenção. Desse modo, pensamos que para explicar o comportamento eleitoral das camadas populares do final dos anos 1980, na perspectiva da História, devem-se levar em consideração as experiências dos homens e das mulheres que foram às urnas, naquele final de década. Trata-se de entender que a cultura política ${ }^{46}$ dos eleitores em qualquer época, e portanto os rumos de uma votação, para além da importância da conjuntura econômica e política de cada momento, também está relacionada com o diálogo estabelecido no passado e no presente entre o campo político e o saber popular adquirido nas experiências da vida cotidiana. Em outras palavras, as razões do voto também dependem do conhecimento que as camadas populares adquiriram ou incorporaram sobre o campo político, entendido como a democracia, as eleições, os partidos, os programas, as ideologias, etc., ao longo do tempo. Esse aspecto, ou cultura política, não pode ser compreendido apenas a curto prazo; é preciso acompanhar como ele se formou historicamente, o que pressupõe observar as suas mudanças e as suas permanências por décadas, ou até mesmo por séculos. Por essa razão, para se conhecer a concepção política ou o

45 BLOCH, Marc, op. cit., p. 55.

46 Em linhas gerais, para a Ciência Política, cultura política designa o conjunto de atitudes, de normas e de crenças mais ou menos largamente partilhadas pelos membros de uma determinada unidade social, tendo como objeto fenômenos políticos. Assim, compõem a cultura política de uma sociedade os conhecimentos ou a sua distribuição entre os indivíduos que a integram, relativos às instituições, à prática política, às forças políticas operantes em um determinado contexto; as tendências mais ou menos difusas, como a indiferença, o cinismo, a rigidez, o dogmatismo; ou o sentido de confiança, a adesão, a tolerância para com as forças políticas diversas da própria, etc. SANI, Giacomo. Cultura política. In: BOBBIO, N.; MATTEUCCI, N.; PASQUINO, G. (Orgs.). Dicionário de política. 9. ed. Brasília: Universidade de Brasília, 1997. p. 306-308. 
comportamento das camadas populares em uma eleição, pode ser necessário estudar a história do seu relacionamento com o campo político, dando particular atenção para os seus valores culturais.

Acreditamos que esta é uma das contribuições que a História pode trazer para o debate sobre a vida política brasileira do final dos anos 1980, ou outros momentos daquela década. A nosso ver, a experiência política do eleitorado que foi às urnas na eleição presidencial brasileira de 1989 também é um elemento muito importante para se entender os rumos da votação na época. Mesmo porque, se consideramos que o processo de democratização política mais amplo no Brasil começou em torno de 1946, e foi interrompido pelo golpe militar em 1964, que nos impôs 21 anos de ditadura, temos, então, aproximadamente apenas quatro décadas de experiência com a democracia política. Isso significa pouco tempo se comparado aos países europeus e aos Estados Unidos.

Lembre-se, também, que em 1989 já haviam-se passado 29 anos sem a realização de eleições diretas para Presidente da República; a última fora em 1960. A maioria do contingente eleitoral daquele final de década nunca havia votado em um mandatário da nação. Mesmo as eleições para os governos estaduais, que haviam sido interrompidas arbitrariamente em 1966, só voltaram a ocorrer em 1982, quando já estava em curso o processo de abertura política. Foi, portanto, um período em que a sociedade brasileira perdeu muitos dos seus direitos: de liberdade de expressão, de opinião e de voto para os principais cargos do executivo. A participação políticoeleitoral ficou restrita às prefeituras - com exceção das capitais, cidades consideradas de segurança nacional - e aos cargos parlamentares. ${ }^{47} \mathrm{Da}$ mesma forma, a eleição presidencial de 1989 foi a primeira que permitiu o voto dos analfabetos e dos jovens com 16 anos de idade. Assim, reiteramos que, além do contexto econômico, político e social da época, essas questões precisam ser levadas em consideração para se entender os resultados daquela eleição.

Feitas essas considerações, gostaríamos de finalizar essa discussão defendendo a idéia de que não existem obstáculos intransponíveis para o historiador estudar o presente. Certamente que ele não pode ser tomado como um dado que se auto-explica, e as evidências, ou os acontecimentos 
nele observados, para serem corretamente entendidos, precisam ser colocados na relação entre passado e presente. Não se trata, evidentemente, de uma volta às origens, mas de saber que para se compreender o que existe, muitas vezes, temos de conhecer como se constituiu historicamente. Ademais, parece ser correto dizer que muitos dos problemas que afetam a atualidade surgiram em outras épocas. Se estivermos certos, excetuando-se eventuais questões ligadas com as fontes, não existe nenhuma outra razão para o historiador esperar décadas para estudar um determinado acontecimento. 